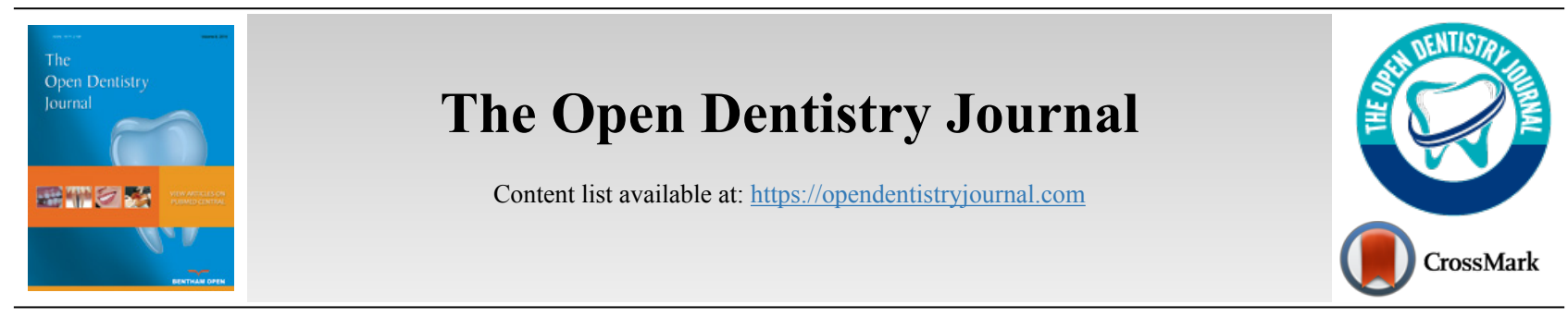

RESEARCH ARTICLE

\title{
Social Media Utilization among Dental Practitioner in Riyadh, Saudi Arabia
}

Abed A-H Hamasha ${ }^{1,2, *}$, Nasser Alghofaili², Abdulrahman Obaid $^{2}$, Mohammed Alhamdan², Abdulrahman Alotaibi ${ }^{2}$, Mohammed Aleissa ${ }^{2}$, Menwer Alenazi ${ }^{2}$, Faisal Alshehri ${ }^{2}$ and Amritha Geevarghese ${ }^{2}$

${ }^{I}$ Department of Preventive Dentistry, Faculty of Dentistry, Jordan University of Science and Technology, Irbid 22110, Jordan

${ }^{2}$ Department of Preventive Dental Science, College of Dentistry, King Saud bin Abdulaziz University for Health Sciences, Riyadh 11481,

Saudi Arabia

\begin{abstract}
:
Objective:

To assess the dental practitioners' use of social media, concerning demographic and social variables and the impact of social media use on denta practice.

Methods:

The study was a cross-sectional analytical study of dental practitioners in Riyadh, Saudi Arabia. A self-administered 30-items questionnaire was distributed to 438 dentists, which included eight questions related to background and demographic information and 22 questions related to the use of social media within the dental practice. Data were entered and analyzed using SPSS software. Data analysis included frequency distributions and chi-square tests to assess the association of social media use with demographic and social variables and its impact on dental practice. Significant level was considered if $p$ was less than 0.05 .

Results:

Of participating, 338 dentists, $52 \%$ were using social media in their practice. Twitter was the most commonly used (35\%). Education was the primary purpose of using social media (43\%), while entertainment was the least ( $8 \%$ ). Approximately $62 \%$ and $68 \%$ are using social media for marketing of their dental practice and broadcasting treatment outcome, respectively. Social media was observed to be used significantly higher among Non-Saudi, general and private dentists. Participating dentists who used social media in their practice significantly recommended using social media to other dentists.

\section{Conclusion:}

In general, non-Saudis, general practitioners and dentists practicing in private clinics are significantly using more social media during their practice. The majority of dental practitioners indicated that social media has improved their dental practice and become an indicator of successful practice.
\end{abstract}

Keywords: Conversational media, Dental literature, Dental practitioners, Social media, Saudi Arabia, Utilization.

\begin{tabular}{|l|l|l|r|}
\hline Article History & Received: January 06, 2019 & Revised: February 01, 2019 & Accepted: February 13,2019 \\
\hline
\end{tabular}

\section{INTRODUCTION}

Social media is defined as activities, practices, and behaviors among communities of people who gather online to share information, knowledge, and opinions using conversational media [1]. There are many forms of social media platforms, including Facebook, Twitter, YouTube, LinkedIn,

\footnotetext{
* Address correspondence to this author at the Department of Preventive Dental Science, College of Dentistry, King Saud bin Abdulaziz University for Health Sciences, P.O.Box.3660 Riyadh, 11426, Kingdom of Saudi Arabia; Tel: 96611 4295725; E-mail: hamashaa@ksau-hs.edu.sa
}

Flickr, Blogs and Wikis [2]. In recent years, the publics' attitude toward the use of social media has undergone a remarkable change as it becomes more variant and accessible [3]. In 2015, a study done by Saudi communication and information technology commission found that $89.77 \%$ of participants used the internet, and $99 \%$ of them are using some form of social media [4]. This reflects the high number of social media users in Saudi Arabia.

For dental practitioners, social media is a useful tool for education and communication with their patients [5]. It is also a valuable tool for marketing [6] as $91 \%$ of dental practitioners 
were found using social media for marketing [7]. The use of social media is age-dependent; hence, younger age groups were more frequent users of social media compared to older age groups [8]. Reviewing the dental literature, studies that assess the dentists' use of social media are lacking. No studies were found to address the use of social media among dental practitioners in Saudi Arabia or the Middle East. This study aims to assess the dental practitioners' use of social media, concerning demographic and social variables, and the impact of social media use on dental practice.

\section{MATERIALS AND METHODS}

The present study was a cross-sectional analytical study of dental practitioners in Riyadh City, Saudi Arabia. The proposal of this study was submitted to the Ethical Committee of King Abdullah Medical Research Center of the National Guard Health Affairs, Saudi Arabia and an IRB for this research was obtained (SP18/4770/R). Human subject protection was taken into consideration by explaining the purpose and the procedure of the current study to participated dentists. Consent forms were then provided to dentists, and only dentists who signed consent forms were given the questionnaires to be answered.

The list of hospitals, centers, and clinics that provide dental services in Riyadh city was obtained from the Ministry of Health. It covers all licensed hospitals and clinics that provide oral health care services. The team members approached the address of these clinics and hospitals. Some of these clinics were not found by the research team.

Most of these places were approached by members of the research team, and an explanation of the purpose of the study was done before the commencement of the study. The list of hospitals, centers, and clinics was obtained from the Ministry of Health.

Participants were eligible to participate in the study if they were licensed to practice dentistry by the Saudi Commission of Health Specialties and treat dental patients as their routine daily activity. Dental specialists were also included. Dentists who hold administrative positions were excluded from the study. Dental students and interns were also excluded.

A self-administered questionnaire was constructed. Questions related to the use of social media were derived from past published literature [7 - 9]. The 30-items question-naire was prepared in English language and consisted of two parts: Part one containing eight questions related to background and demographic information of dentists, including age, gender, nationality, dental specialty, working sector, Monthly income in Saudi Riyals, the location of work, and hours worked per week. Part two consists of 22 questions to assess types of social media users, the use of social media within a dental practice, and the effect of social media on dental practice and patients. The final questionnaires were distributed to selected private and government dental clinics in different areas in Riyadh city during January 2018.

A pilot study that consisted of 10 participants to pretest the questionnaire was conducted to ensure that the questionnaire was comprehensible to the dentists and to identify any problems within questions. The questionnaire was then modified, and a few minor changes were made according to the outcome of the pilot study.

Data were entered and analyzed into the Statistical Package for Social Sciences (SPSS) software version 22 (IBM Inc., Chicago, IL, USA). Data analysis included frequency distribution with numbers and percentages, in addition to Chi-square tests to assess the association of social media use with demographic and social variables and its impact on dental practice. Significant level was considered if $p$ was less than 0.05 .

\section{RESULTS}

Of the 438 distributed questionnaires a total number of 338 responses were complete, with an overall response rate of $77.2 \%$. Table.1 presented demographic and background characteristics of the study sample. About $38 \%$ of participants were of younger age, followed by $33 \%$ in the $31-40$ years age group, and only $11.5 \%$ of participants aged 50 years or more. Approximately $61.5 \%$ of the participants were males, and $38.5 \%$ were females. Saudi participants comprised less than half of the participants (42\%). More than half of the participants of this study were general practitioners $(54.1 \%)$ and were working within the private sector (54.4). More than half of dentists were practicing in the East side of Riyadh (51.2), and three-quarters were receiving high monthly income. Also, about 59\% were working 40 hours and above per week.

Table. 2 showed the frequency distribution of social media use among dental practitioners. The percentage of dentists using social media within their practice was $52 \%$. However, from the 163 dentists who were not using social media, $33 \%$ were planning to use them in the future. Among social media users, the most commonly used media was Twitter (35\%) followed by Facebook (20\%) while WhatsApp (4\%) was the least commonly used. Education was reported by $43 \%$ of the dentists as the primary purpose of using social media, advertisement by $39 \%$ while entertainment was reported the least $(8 \%)$. Of participants who are using social media, $62 \%$ and $68 \%$ used them for marketing of their dental practice and broadcasting treatment outcome online to attract patients, respectively. About $59 \%$ of participants used social media to give online consultation at some instances.

Table. 3 demonstrated the using of social media by dentists within the practice of dentistry concerning their demographic and social variables. Social media was observed to be used significantly higher among Non-Saudi dentists com-pared to Saudi dentist $(P$-value $\leq 0.001)$. There was a signi-ficant increase in usage of social media among general practi-tioner and private practitioners compared to the specialist $(p=0.029)$ and governmental dentists $(P$-value $<0.001)$, respec-tively. The usage of social media was significantly varying between 37.5 to $60 \%$ among different monthly income categories. The Age, gender, and location of dental practice have no significant influence on social media usage.

Table. 4 presents the relationship between the use of social media and its impact on dental practice. Participating dentists who used social media in their practice significantly recommended using social media to other dentists and claimed that social media improved their dental practice. Additionally, these dentists believed that social media is an indicator of successful dental practice. 
Table 1. Demographic and background characteristics of study sample.

\begin{tabular}{|c|c|c|c|}
\hline Variable & Category & No. & $\%$ \\
\hline \multirow{4}{*}{ Age } & $20-30$ & 129 & 38.2 \\
\hline & $31-40$ & 113 & 33.4 \\
\hline & $41-50$ & 57 & 16.9 \\
\hline & $50+$ & 39 & 11.5 \\
\hline \multirow{2}{*}{ Gender } & Male & 208 & 61.5 \\
\hline & Female & 130 & 38.5 \\
\hline \multirow{2}{*}{ Nationality } & Saudi & 142 & 42.0 \\
\hline & Non-Saudi & 196 & 58.0 \\
\hline \multirow{2}{*}{ Dental specialty } & General practitioners & 183 & 54.1 \\
\hline & Specialists & 155 & 45.9 \\
\hline \multirow{3}{*}{ Working sector } & Government & 116 & 34.3 \\
\hline & Private & 184 & 54.4 \\
\hline & Both & 38 & 11.2 \\
\hline \multirow{4}{*}{ Location of practice } & North of Riyadh & 66 & 19.5 \\
\hline & East of Riyadh & 173 & 51.2 \\
\hline & South of Riyadh & 75 & 22.2 \\
\hline & West of Riyadh & 24 & 7.1 \\
\hline \multirow{4}{*}{ Monthly income } & Less than SR15,000 & 79 & 23.4 \\
\hline & SR15,000-SR20,000 & 114 & 33.7 \\
\hline & SR20,000-SR25,000 & 65 & 19.2 \\
\hline & More than SR25,000 & 80 & 23.7 \\
\hline \multirow{4}{*}{ Hours of working per week } & Less than 20 hours & 9 & 2.7 \\
\hline & 20-40 hours & 130 & 38.5 \\
\hline & 41-50 hours & 146 & 43.2 \\
\hline & More than 50 hours & 53 & 15.7 \\
\hline
\end{tabular}

Table 2. Frequency distribution of the social media use among dental practitioners.

\begin{tabular}{|c|c|c|c|}
\hline Variable & Category & No. & $\%$ \\
\hline \multirow{2}{*}{ Using social media within the practice of dentistry } & Yes & 175 & 51.8 \\
\hline & No & 163 & 48.2 \\
\hline \multirow{3}{*}{ Planning to use social media in the future } & Yes & 53 & 32.5 \\
\hline & No & 77 & 47.2 \\
\hline & Not sure & 33 & 9.8 \\
\hline \multirow{6}{*}{ Most commonly used social media platforms } & Twitter & 62 & 35.4 \\
\hline & Facebook & 35 & 20.0 \\
\hline & Instagram & 30 & 17.1 \\
\hline & Snapchat & 24 & 13.7 \\
\hline & YouTube & 17 & 9.7 \\
\hline & WhatsApp & 7 & 4.0 \\
\hline \multirow{4}{*}{ The purpose of using social media } & Education & 76 & 43.4 \\
\hline & Advertisement & 68 & 38.9 \\
\hline & Communication & 17 & 9.7 \\
\hline & Entertainment & 14 & 8.0 \\
\hline \multirow{2}{*}{ Use social media as marketing tool } & Yes & 109 & 62.3 \\
\hline & No & 66 & 37.7 \\
\hline \multirow{2}{*}{ Broadcast treatment outcome online to attract patients } & Yes & 119 & 68.0 \\
\hline & No & 56 & 32.0 \\
\hline \multirow{2}{*}{ Giving online consultation to patients } & Yes & 103 & 58.9 \\
\hline & No & 72 & 41.1 \\
\hline
\end{tabular}


Table 3. Using social media within the practice of dentistry in relation to demographic and social variables.

\begin{tabular}{|c|c|c|c|c|c|c|c|c|}
\hline \multirow[t]{2}{*}{ Variable } & \multirow[t]{2}{*}{ Category } & \multicolumn{2}{|c|}{\begin{tabular}{|c|}
$\begin{array}{c}\text { Social Media Usage } \\
\text { Yes }\end{array}$ \\
\end{tabular}} & \multicolumn{2}{|c|}{\begin{tabular}{|c|} 
Social Media Usage \\
No
\end{tabular}} & \multirow[t]{2}{*}{ Total } & \multirow[t]{2}{*}{$\%$} & \multirow[t]{2}{*}{$P$-value } \\
\hline & & No & $\%$ & No & $\%$ & & & \\
\hline \multirow{4}{*}{ Age } & $20-30$ & 73 & 56.6 & 56 & 43.4 & 129 & 38.2 & \multirow{4}{*}{0.514} \\
\hline & $31-40$ & 57 & 50.4 & 56 & 49.6 & 113 & 33.4 & \\
\hline & $41-50$ & 26 & 45.6 & 31 & 54.4 & 57 & 16.9 & \\
\hline & 50 or more & 19 & 48.7 & 20 & 51.3 & 39 & 11.5 & \\
\hline \multirow{2}{*}{ Gender } & Male & 111 & 53.4 & 97 & 46.6 & 209 & 61.5 & \multirow{2}{*}{0.503} \\
\hline & Female & 64 & 49.2 & 66 & 50.8 & 130 & 38.5 & \\
\hline \multirow{2}{*}{ Nationality } & Saudi & 51 & 35.9 & 91 & 64.1 & 142 & 42 & \multirow{2}{*}{$\leq 0.001 *$} \\
\hline & Non-Saudi & 124 & 63.3 & 72 & 36.7 & 196 & 58 & \\
\hline \multirow{2}{*}{ Specialty } & General Practitioner & 105 & 57.4 & 78 & 42.6 & 183 & 54.1 & \multirow{2}{*}{$0.029 *$} \\
\hline & Specialist & 70 & 45.2 & 85 & 54.8 & 116 & 34.3 & \\
\hline \multirow{3}{*}{ Work Sector } & Government & 51 & 44.0 & 65 & 56.0 & 184 & 54.4 & \multirow{3}{*}{$\leq 0.001 *$} \\
\hline & Private & 113 & 61.4 & 71 & 38.6 & 196 & 58 & \\
\hline & Both & 11 & 28.9 & 27 & 71.1 & 38 & 11.2 & \\
\hline \multirow{4}{*}{ Monthly Income } & Less than SR15,000 & 45 & 57.0 & 34 & 43 & 79 & 23.4 & \multirow{4}{*}{$0.026^{*}$} \\
\hline & SR15,000 - SR20,000 & 61 & 53.5 & 53 & 46.5 & 114 & 33.7 & \\
\hline & SR21,000 - SR25,000 & 39 & 60.0 & 26 & 40 & 65 & 19.2 & \\
\hline & more than SR25,000 & 30 & 37.5 & 50 & 62.5 & 80 & 23.7 & \\
\hline \multirow{4}{*}{ Location of Practice } & North of Riyadh & 33 & 50 & 33 & 50 & 66 & 19.5 & \multirow{4}{*}{0.450} \\
\hline & East of Riyadh & 84 & 48.6 & 89 & 51.4 & 173 & 51.2 & \\
\hline & South of Riyadh & 44 & 58.7 & 31 & 41.3 & 75 & 22.2 & \\
\hline & West of Riyadh & 14 & 58.3 & 10 & 41.7 & 24 & 7.1 & \\
\hline
\end{tabular}

* Statistically significant using Chi square test

Table 4. Use of the social media and its impact on dental practice.

\begin{tabular}{|c|c|c|c|c|c|c|c|c|}
\hline \multirow[t]{2}{*}{ Variable } & \multirow[t]{2}{*}{ Category } & \multicolumn{2}{|c|}{\begin{tabular}{|c|} 
Social Media Usage \\
Yes
\end{tabular}} & \multicolumn{2}{|c|}{\begin{tabular}{|c|} 
Social Media Usage \\
No
\end{tabular}} & \multirow[t]{2}{*}{ Total } & \multirow[t]{2}{*}{$\%$} & \multirow[t]{2}{*}{$P$ - value } \\
\hline & & No & $\%$ & No & $\%$ & & & \\
\hline \multirow{2}{*}{ Recommend social media usage to other dentists } & Yes & 160 & 62.7 & 95 & 37.3 & 255 & 75.4 & \multirow{2}{*}{0.000} \\
\hline & No & 15 & 18.1 & 68 & 81.9 & 83 & 24.6 & \\
\hline \multirow{3}{*}{ Use of social media improved dental practice } & Yes & 115 & 66.5 & 58 & 33.5 & 173 & 51.2 & \multirow{3}{*}{0.000} \\
\hline & No & 33 & 37.9 & 54 & 62.1 & 87 & 25.7 & \\
\hline & Not sure & 27 & 34.6 & 51 & 66.4 & 78 & 23.1 & \\
\hline \multirow{2}{*}{ Social media became an indicator for successful dental practice } & Yes & 110 & 65.1 & 59 & 34.9 & 169 & 50 & \multirow{2}{*}{0.000} \\
\hline & No & 65 & 38.5 & 104 & 61.5 & 169 & 50 & \\
\hline
\end{tabular}

* Statistically significant using Chi square test

\section{DISCUSSION}

The present study aimed to assess the use of social media among dental practitioners and to investigate the potential effects of it among dental practice. However, reviewing the dental literature, there was a lack of published literature on the exact effect of social media on dental practitioners. Moreover, this is the first study to assess the use of social media among dental practitioners in Saudi Arabia.

Social media has spread widely around the globe and become a connecting tool between dentists and patients [10]. Currently, many published literature has reported social media to play a significant role in health care related practice, and their influence on the field of dentistry has also been observed $[7-9,11]$.
In an attempt to include all dental practitioners, both specialists and general who are working in both private and governmental sectors were approached personally in their clinics. This will give more confidence in our outcome since we can include users and non-users of social media as well as it will increase the participating rate. Other studies conducted among American [7,9] and South African [8] dental practitioners used questionnaires distributed online which might affect the result since most social media users are the ones who received the questionnaires and responded to them.

In the present study, the dentists who were using social media within their dental practice were $52 \%$. This result is similar to the findings from USA dentists who were using social media (51\%) within their practices [7]. Twitter was the most commonly used platform among Saudi dentists; however, 
other studies reported that Facebook was the most commonly used platform [7 - 9]. This could be attributed to the fact that Twitter is the most commonly used platform in Saudi Arabia according to the Saudi Communication and Information Technology Commission, which enables the dentists to target a higher number of people [4]. In this study, the use of social media by non-Saudi dentists was higher compared to Saudi dentists. This could be explained by Non-Saudi dentists' digital background and their capability of using different platforms of social media. The use of all types of Social media in Saudi Arabia is not restricted. Dentists can open their account or clinic accounts on all types of Social media without limitation of access. However, the material used should be in respect to social norms and Islamic rules.

General practitioners were using social media within their practice more often than did specialists. This result is similar to the other findings [7]. This could be contributed to the fact that general practitioners earned less compared to specialists; therefore they seek out more opportunities to attract more patients. Furthermore, the majority of the workforce of private clinics consisted of non-Saudis generalists.

Snyman et al., (2014) showed that $13.2 \%$ of the South African dentists were using social media as a marketing tool [8]. This came in contrary to the present study where $62 \%$ of the participants indicated the use of social media for marketing. Additionally, $86 \%$ of the participants in this study predicted that the use of social media, as a marketing tool, will increase in the future. This result is similar to the findings of the study mentioned earlier [8] where $83.5 \%$ of the participants predicted that social media marketing would increase in the future. This could be attributed to an unprecedented increase in the use of social media among people.

In our study, $43 \%$ of our participants indicated that the primary purpose of using social media was for education. However, $91 \%$ of the participants indicated that marketing was the primary purpose of using social media among USA dentists [8]. Since most of our participants were from the younger age group, who are more enthusiastic for educating themselves using social media, this might explain the difference from the other study whose age groups were older.

The sample of dentists was obtained from the list of hospitals and clinics practicing dentistry in Riyadh city. Most areas were approached, and the available dentists were asked to participate in the present study. However, three was no other better information about the specific real distribution of dentists in Riyadh city. Additionally, about $23 \%$ of the approached dentists did not sign the consent forms or did not fill the distributed questionnaires. Therefore, the generalization of the results of the present study to all dental practitioners in Riyadh city should be considered with caution due to the reasons mentioned above.

The distributed questionnaires were only in the English language; however, some dentists might have their education in different language and might have a weak background in this language which might their participation in the study or understanding the questions. A further nationwide study should include a questionnaire built in both Native and English languages. Utilization of social media by patients and practitioners who are not fluent in English might have an impact on the utilization of social media presented in the English language. However, online Arabic resources are abundant and might be of greater utility to many patients [12]. Such a resource might be precious if these social media were primarily used as a marketing tool.

Our results can help dental practitioners to understand their responsibility of using social media within their dental practice, which will be reflected in patients' expectations and knowledge. The findings of this study might help Saudi Commission for Health Specialties to organize workshops to harmonize the use of social media within the dental practice to avoid any ethical violations of their use among dental practitioners in Saudi Arabia.

\section{CONCLUSION}

This study found that about $52 \%$ of participating dentists in Saudi Arabia use social media in their practice. Twitter was the most commonly used platform, and education was the primary purpose of using social media within the dental practice. In general, non-Saudis, general practitioners and dentists practicing in private clinics are significantly using more social media within their practice. The majority of dental practitioners indicated that social media has improved their dental practice and has become an indicator of successful practice.

\section{ETHICS APPROVAL AND CONSENT TO PARTICIPATE}

Ethical approval was obtained from the IRB committee of King Abdullah Medical Research Center Saudi Arabia (SP18/4770/R).

\section{HUMAN AND ANIMAL RIGHTS}

No animals were used for studies that are the basis of this research.All research procedures followed were in accordance with the Helsinki Declaration of 1975, as revised in 2013. Written informed consent for participation was obtained from each participant.

\section{CONSENT FOR PUBLICATION}

Informed consent was signed by the participants.

\section{FUNDING}

None.

\section{CONFLICT OF INTEREST}

The authors declare no conflict of interest, financial or otherwise.

\section{ACKNOWLEDGEMENT}

None declared.

\section{REFERENCES}

[1] Safko J, Brake DK. The social media bible: Hoboken. NJ: Wiley 2009.

[2] Thielst CB. Social media: Ubiquitous community and patient engagement. Front Health Serv Manage 2011; 28(2): 3-14.

[http://dx.doi.org/10.1097/01974520-201110000-00002] [PMID: 2225 6506]

[3] Sarringhaus MM. The great divide: Social media's role in bridging healthcare's generational shift. J Healthc Manag 2011; 6(4): 235-44. [http://dx.doi.org/10.1097/00115514-201107000-00005] [PMID: 2183 
8022]

[4] Saudi Communication and Information Technology Commission [cited 1 May 2017]Available from 2015.http://www.citc.gov.sa/ ar/ reportsandstudies/studies/Documents/ PublicIndividualReport2015V5 Ar.pdf

[5] McAndrew M, Johnston AE. The role of social media in dental education. J Dent Educ 2012; 76(11): 1474-81. [PMID: 23144483]

[6] Evans D. Social Media Marketing: An Hour a Day. London: Wiley Publishing Inc 2008; p. 31.

[7] Henry RK, Molnar A, Henry JC. A survey of US dental practices' use of social media. J Contemp Dent Pract 2012; 13(2): 137-41. [http://dx.doi.org/10.5005/jp-journals-10024-1109] [PMID: 22665 737]

[8] Snyman L, Visser JH. The adoption of social media and social media marketing by dentists in South Africa. SADJ 2014; 69(6): 258-64
[PMID: 26548200]

[9] Nelson KL, Shroff B, Best AM, Lindauer SJ. Orthodontic marketing through social media networks: The patient and practitioner's perspective. Angle Orthod 2015; 85(6): 1035-41.

[http://dx.doi.org/10.2319/110714-797.1] [PMID: 25738 740]

[10] Parmar N, Dong L, Eisingerich AB. Connecting with your dentist on facebook: Patients' and dentists' attitudes towards social media usage in dentistry. J Med Internet Res 2018; 20(6): e10109.

[http://dx.doi.org/10.2196/10109] [PMID: 29959 108]

[11] Neville P, Waylen A. Social media and dentistry: Some reflections on e-professionalism. Br Dent J 2015; 218(8): 475-8.

[http://dx.doi.org/10.1038/sj.bdj.2015.294] [PMID: 25908 363]

[12] El Tantawi M, Bakhurji E, Al-Ansari A, Al Subaie A, Al Subaie HA, Al-Ali A. Indicators of adolescents' preference to receive oral health information using social media. Acta Odontol Scand 2019; 11: 1-6. [http://dx.doi.org/10.1080/00016357.2018.1536803] [PMID: 30632 864]

(C) 2019 Hamasha et al.

This is an open access article distributed under the terms of the Creative Commons Attribution 4.0 International Public License (CC-BY 4.0), a copy of which is available at: (https://creativecommons.org/licenses/by/4.0/legalcode). This license permits unrestricted use, distribution, and reproduction in any medium, provided the original author and source are credited. 